\title{
Food for all
}

$\mathrm{H}$ unger. In Canada it's tough to diagnose, but it is a pervasive factor in the health of thousands across the country. Every month, some 753000 Canadians depend on charitable handouts from food banks to stave off hunger or alleviate undernourishment. ${ }^{1}$ In Toronto, 50\% of food-bank users still go hungry at some point every month, which is more frequently than they did a decade ago. ${ }^{2}$

Most Canadians who suffer from hunger are ashamed to admit it, and the $90 \%$ of Canadians who are unaffected in any given year have difficulty relating to hunger. ${ }^{3}$ Even short-term food deprivation can affect the physical and mental development of young children who are disproportionately represented in the ranks of Canada's hungry ( $4 \mathrm{I} \%$ compared with $25 \%$ in the population at large). ${ }^{1}$ And the psychological torment of being denied the satisfaction of a good meal preys on children and adults alike. Unfortunately, little is known in the Canadian context of the extent to which chronic or episodic hunger are related to morbidity; much of the data does not easily distinguish between cause and effect from the overrepresentation of ill and disabled people among the very poor.

It is an intuitive conclusion and a moral imperative to recognize hunger as one of the most preventable and significant health issues facing Canadian society. For more than 25 years, food banks have been the principal response to hunger in most of our major cities and smaller towns. Many food banks, which were meant to be temporary, have outlasted the recessions that gave rise to them and have been forced to acquire the trappings of permanency, including trucks, warehouses, paid staff, volunteers, and donated goods and services. Food banks are, de facto, relief agencies in a country with a secure food supply.

A more ambitious country would not accept this. If we thought of hungry Canada as a city of 750 ooo people, it would be the seventh largest in the country, just ahead of Québec. If this city was under attack by forest fires or flood, we would rush not only to give aid, but also to help people rebuild and get on with their lives. We would not leave them vulnerable for years on end.

During the holiday season, our own tables will teem with good food. And, for a few fleeting days, perhaps even the entire week before Dec. 25, food-bank request phone lines will go silent as supply actually meets demand. But it is during the following week - the one in which we make New Year's resolutions - that conscientious Canadians should set their sights on improvement throughout the year.

Family breakdown, illness, injury, unemployment, lower education, overpriced housing and recent immigration did not previously mean nutritional purgatory for so many Canadians.

This generation of Canadians can resolve to have a hunger-free country. This will only happen when we stop relying solely on the considerable efforts of individuals affected and of aid organizations, and when we stop blaming hungry people themselves. The real shame of hunger does not belong with those who go without. Rather, shame belongs with those of us who eat well and who are prepared to accept this divide.

Two principles are key to solving hunger. First, children should never go hungry. A substantial step would be a new national child-income benefit that is adequate, protected from clawbacks and sent directly to parents. Second, every citizen has a right to participate in society. This would entail providing every disadvantaged adult with a fair chance for advancement. Financial programs must be tied to the actual cost of basic needs in our communities. Timely "secondchance" transition programs must link anti-hunger efforts to new anti-poverty initiatives in education, mentorship, child care and employment incentives, tapping people's powerful desire to get ahead.

But none of this will happen unless Canadians demand it. And no group could be better placed than Canada's physicians to start a commitment to eliminate hunger. Typically, more than half of the adults using food banks are disabled or seriously ill. ${ }^{2}$ This means that, as a doctor, you can witness and report on the face of hunger. If you choose, you and other doctors, working with the considerable collective power of the Canadian Medical Association, can be the catalyst for long-overdue decisive action to benefit some of your most needy patients and fellow citizens.

Canada will be stronger when we defeat hunger within our borders. A better workforce, lower health care costs, a lot less suffering - think of it as the very best gift you can give this holiday season.

\section{Gerard Kennedy}

Distinguished Visiting Professor, Ryerson University Toronto, Ont.

With the Editorial-Writing Team (Paul C. Hébert MD MHSc, Matthew B. Stanbrook MD PhD, Barbara Sibbald BJ, Ken Flegel MDCM MSc, Noni MacDonald MD MSc and Amir Attaran LLB DPhil)

\section{REFERENCES}

I. Canadian Association of Food Banks. Hungercount 2006. Toronto: The Association; 2006.

2. Daily Bread Food Bank. Who's hungry: 2007 profile of hunger in the GTA. Toronto: The Daily Bread Food Bank; 2007.

3. Health Canada. Canadian Community Health Survey Cycle 2.2, Nutrition (2004) Income-related household food security in Canada. Ottawa: Health Canada; 2007 , Cat no Hr64-42/2007E-PDF. Available: www.hc-sc.gc.ca/fn-an/surveill/nutrition /commun/income_food_sec-sec_alim_e.html (accessed 2007 Nov 4). 